\title{
De la Administración Pública tradicional a la nueva gestión pública. Ensayo sobre la experiencia modernizadora de diversos países desarrollados
}

\section{Patrick Dunleavy y Christopher Hood *}

La expresión "Nueva Gestión Pública" (NGP) es controvertida. Frecuentemente se utiliza como un término genérico, como una formulación útil para resumir y describir como las diferentes partes de la Administración pública se reorganizan y adoptan unos mecanismos de actuación más cercanos a los que -desde una determinada percepción del sector privado- se emplean en el mundo empresarial. Utilizando la jerga académica, la consolidación de la NGP conlleva una transformación de los modelos de gestión del sector público que opera en dos direcciones: "downgrid" y "down-group" (Douglas, 1982). El movimiento "downgroup" supone que el sector público se diferencia menos del sector privado en términos de personal, estructura de salarios, métodos de actuación, etc. El movimiento "down-grid", por su parte, implica una reducción de los límites que la uniformidad y la rigidez de las reglas y de los procedimientos imponen sobre la actuación de la Administración pública; especialmente, otra vez, en términos de personal, contratos o estructura financiera. Estas transformaciones contrastan con la Administración pública tradicional, característica de la llamada época progresista y edificada sobre la idea de un sector público claramente diferenciado del exterior (group) y densamente uniforme respecto a sus reglas y procedimientos internos (grip). La figura 1 nos muestra la dirección de estos cambios, los cuales pueden ser formulados más concretamente a través de los siguientes puntos:

- Modificaciones presupuestarias destinadas a mejorar la transparencia contable y a relacionar los costes no con los recursos utilizados sino con los resultados obtenidos (con la necesidad de elaborar indicadores que nos sirvan para medir los resultados que esto conlleva).
* Observar las organizaciones como una cadena de relaciones de baja confianza entre un actor principal y unos agentes secundarios '; es decir, como una red de contratos capaces de adecuar los incentivos con los resultados.

* Desagregar las tareas de la Administración pública a través de fórmulas semi-contractuales o semi-mercantiles y, en particular, introducir la distinción comprador-proveedor para así sustituir las tradicionales estructuras unificadas de prestación y planificación funcional

* Fomentar la competencia entre entes públicos, empresas privadas y organizaciones no lucrativas que pretendan prestar un determinado servicio público.

- Descentralizar la provisión hasta el tamaño más reducido posible, facilitando a los usuarios un mayor margen para optar

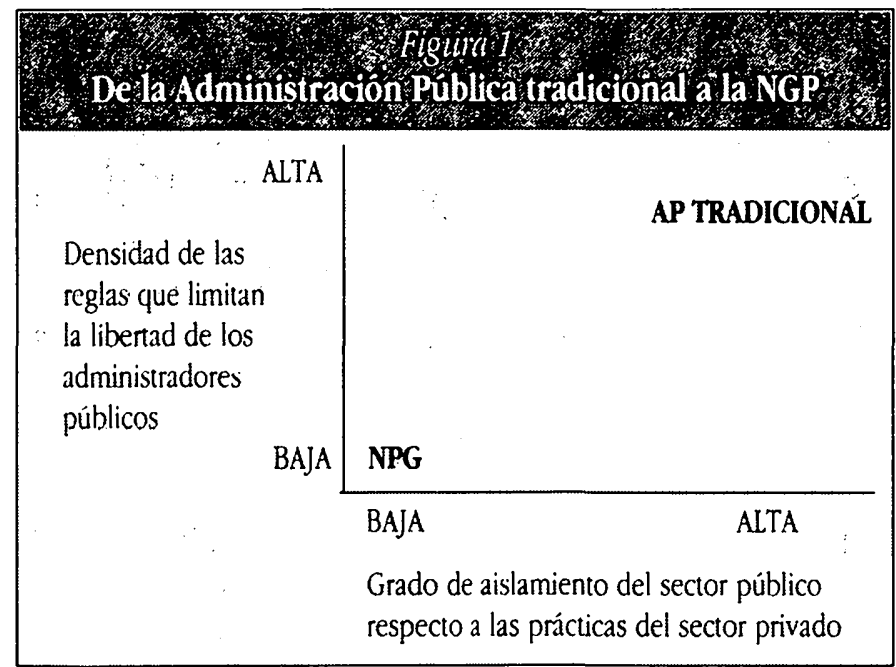


entre proveedores alternativos ("exit option") más que obsesionándose por cómo estos usuarios se manifiestan sobre los efectos de los servicios que reciben ("voice option") 2.

Queremos subrayar que no estamos afirmando que con la NGP se reduzca en general el volumen de todo tipo de regulación. Por ejemplo, la contratación que pretende especificar detalladamente el tipo de servicio esperado produce una gran cantidad de documentación y, quizás, una formalización de las condiciones de provisión más acentuada que antes. Sin embargo, estas decisiones tan detalladas se realizan caso a caso, y son sustancialmente diferentes respecto a las regulaciones y las condiciones administrativas asociadas a los métodos de la Administración pública tradicional.

Experiencias ya conocidas de reforma administrativa sugieren, como mínimo, dos alternativas posibles para que un movimiento como el de la NGP pueda consolidarse (PoLSBY, 1984). La primera es conocida como el "modelo incubadora" y se caracteriza porque las ideas de reforma no logran un efecto pleno hasta que no ha transcurido un largo periodo desde su introducción, hasta que no se instalan definitivamente como una nueva ortodoxia. Un claro ejemplo del "modelo incubadora" lo encontramos en las propuestas del informe Northcote-Trevelyan de 1854. En sus orígenes, este proyecto fue ampliamente rechazado, ya que se le acusaba de incorporar demasiado acríticamente las experiencias históricas de la antigua China y, por lo tanto, de ser excesivamente ajeno a la realidad operativa de la Administración pública del siglo XIX. Sin embargo, a finales del mismo siglo XIX, sus propuestas, aunque un tanto modificadas, se convirtieron en la forma convencional de entender la Administración pública.

Un modelo alternativo para hacer efectivas las estrategias de reforma es el llamado "modelo de innovación aguda", que se identifica por la temprana introducción y la también rápida desintegración de los programas de reforma. Una muestra clásica de este modelo se puede ilustrar a través de la corta vida del programa de planificación corporativa que se instaló en el gobierno local británico a mediados de la década de los setenta. El temprano carácter evangélico del "modelo de innovación aguda" produce una clonificación general de sus propuestas. Esta clonificación da paso a una inmediata desilusión, provocada por la introducción de unas prácticas demasiado novedosas y ajenas a la tradición administrativa, las cuales rompen con la seguridad de lo conocido. A menudo, esta desilusión se produce también como respuesta a una retirada del apoyo político o a la reafirmación de otros valores.

La NGP parece disponer de elementos propios de ambos estilos de reforma. Las diferentes iniciativas individuales pueden responder al "modelo de innovación aguda", mientras que el conjunto del movimiento reformador se nos presenta más bien bajo la forma del "modelo incubadora". Muchas de las propues- tas atribuidas a la NGP parecen respuestas a ideas desarrolladas durante los años sesenta (por ejemplo, en el ámbito local, el control de las empresas públicas y el informe Fulton), pero no aplicadas en ese momento por las corrientes dominantes dentro de la Administración Pública. La NGP, además, ha sido capaz de ir acomodando sus propuestas de cambio durante un dilatado período de tiempo. Mantiene sus grandes estrategias "downgroup" y "doun-grip", pero se despliega a través de una amplia variedad de formas en función de las peculiaridades de cada contexto; sin contar, en ningún caso, ni con un único momento de gran expansión ni con un único manual de actuación. Se ha difundido de un ámbito a otro del sector público, ha pasado de modelos simples a modelos más complejos y, en general, ha optado por dar unos primeros pasos seguros para sólo más tarde aventurarse con estrategias de más amplio alcance. Un ejemplo británico de este proceder lo encontramos en el paso de la "agencialización" a la "mercantilización" de las estructuras administrativas; o, en el caso de Nueva Zelanda, en el tránsito del presupuesto por resultados a las prácticas de auditoría operativa.

Por otro lado, la NGP ha llegado a ser identificada internacionalmente con la inevitable "marcha de la bistoria", especialmente gracias al papel desempeñado por el libro de OSBORNE y GAEBLER - La Reinvención del Gobierno- en la campaña electoral de Bill Clinton en $1992^{3}$. Casos opuestos, como los de Alemania y Suiza, son convenientemente ignorados cuando se formulan este tipo de afirmaciones. Finalmente, la oposición políica a la NGP no ha crecido sino que, al contrario, ha retrocedido: la hostilidad inicial de la izquierda en relación a las privatizaciones y a determinadas formas de descentralizar y de usar los indicadores de resultados ha mitigado rápidamente una vez las reformas se han puesto en funcionamiento.

Podemos incluso pensar que la NGP es hoy por hoy algo tan omnipresente dentro del sector público que difícilmente deja espacio para cualquier otro programa de reforma alternativo. Pero si actualmente la NGP lo es todo, también podría suceder que no fuera nada, que no representara realmente una forma peculiar de gestionar las organizaciones. Cuando Max WeBER, en 1911, describió su famoso tipo ideal burocrático, las características utilizadas para definirlo (tales como la distinción entre funciones y personas, la estructura jerárquica, la confianza en los procedimientos escritos y reglados, o el énfasis en la creación de una administración ajena a los intereses particulares) también servían como rasgos distintivos, como elementos no compartidos por otras organizaciones. Ochenta años más tarde, el tipo ideal weberiano ha perdido su fuerza innovadora y se ha convertido en sinónimo de "organización". Quizá sucederá lo mismo con la NGP, y podría ser que en un lapso de tiempo mucho más corto. Quizá todo lo que no es NGP se nos presenta como algo tan anacrónico como la organización colegiada contra la que Max WeBER desplegó sus argumentos. Quizá cuando hoy hablamos 
de "organización", en cualquier sector de la sociedad, el concepto nos remite automáticamente al presupuesto por objetivos, a los indicadores de resultados, a la separación de los roles, o a la imagen de una red compleja de contratos.

Si lo sugerido hasta el momento tiene alguna fuerza, se pueden apuntar dos consecuencias. En primer lugar, se podría pensar que aquéllos que observan la NGP únicamente como un programa de reforma más están enganándose y tampoco están entendiendo el nivel normal del flujo organizativo para un proyecto sustantivo de reforma. En segundo lugar, se podría sugerir que todos los interrogantes que plantea la NGP tienen relación con las diferencias entre sus múltiples aplicaciones, así como con las diferentes formas de usar los nuevos instrumentos organizativos.

\section{Críticas a la NGP: Costes y problemas}

La NGP, como todos los sistemas de gestión, despierta una mezcla de odios y de pasiones. Ya que los elogios son suficientemente conocidos, este artículo se concentra en las críticas. En general, éstas se pueden clasificar en cuatro grupos: las fatalistas, las individualistas, las jerárquicas y las igualitarias. Estas etiquetas provienen de las teorías culturales, donde se utilizan para captar un amplio espectro de actitudes de la población como, por ejemplo, su visión subyacente respecto a la naturale-

\begin{tabular}{|c|c|}
\hline $\begin{array}{l}\text { Critica fatalista: } \\
\text { La NGP no puede hacer frente a los } \\
\text { dilemas básicos de la Administración } \\
\text { Pública. } \\
\text { Alternativa: } \\
\text { Ninguna, sobrevalorar los sistemas } \\
\text { de gestión los hace vulnerables a los } \\
\text { ataques fatalistas. }\end{array}$ & $\begin{array}{l}\text { Critica jerárquica: } \\
\text { La NGP puede erosionar la cohesión } \\
\text { del sistema y sinuar al sector público } \\
\text { fuera de control. } \\
\text { Alternativa: } \\
\text { Fortalecer la capacidad de control } \\
\text { ceniral e incrementar las obligacio- } \\
\text { nes de consulta. }\end{array}$ \\
\hline $\begin{array}{l}\text { Critica individualista: } \\
\text { La NGP corre el riesgo de convertir- } \\
\text { se en un sustitutivo mediocre de los } \\
\text { derechos contractuales individuales. } \\
\text { Alternativa: } \\
\text { Más contratos reales y menos quasi- } \\
\text { contratos, más privatización y } \\
\text { menos corporatización. }\end{array}$ & $\begin{array}{l}\text { Crítica igualitaria: } \\
\text { La NGP puede fomentar la comup- } \\
\text { ción, acomodarse a los intereses } \\
\text { personales de los altos funcionarios } \\
\text { y debilitar las responsabilidades. } \\
\text { Alternativa: } \\
\text { Más cesión de poder a los ciudada- } \\
\text { nos, más mecanismos anticorrup- } \\
\text { ción, extender el modelo del rol } \\
\text { empresarial, imponer un control } \\
\text { estricto sobre los posibles fraudes } \\
\text { en los contratos. }\end{array}$ \\
\hline
\end{tabular}

za y las actitudes hacía el riesgo (SChWarz y Thompson, 1990). Las categorías de la teoría cultural atraviesan precisamente el terreno más conocido de la dicotomía izquierda-derecha, una útil característica para acercarse a las reformas administrativas. Ya que las cuatro grandes críticas a la NGP son contradictorias entre sí, podemos aprender algo de cada una de ellas. Lo hemos resumido en la figura 2.

\section{La critica fatalista}

Según las teorías culcurales, las personas fatalistas no creen en la posibilidad de controlar la naturaleza o las interacciones humanas que se producen en su interior. Trasladándonos al terreno de la reforma administrativa, la posición fatalista mantiene que los problemas básicos de la gestión en el sector público -los errores humanos, los fallos del sistema, los programas mal diseñados, el fraude y la corrupción, o las malas intencionesson omnipresentes. Ningún sistema de gestión, ya sea la NGP, la administración convencional o cualquier otra cosa, puede eliminar estos problemas. Desde este punto de vista, no hay bubris sin nemesis, no existen varitas mágicas ni soluciones fáciles para resolver los problemas esenciales de la Administración Pública. Los fatalistas son particularmente conscientes frente a la evidencia de que muy poco está cambiando bajo el manto de una nueva sigla (NGP) y del renovado esquema de control promovido por la NGP, y, consecuentemente, proclaman el colapso y el fracaso de un sistema impuesto a bombo y platillo.

La crítica fatalista es indudablemente negativa, ya que pretende destruir las ambiciones de la NGP sin presentar un programa alternativo mínimamente definido. Los defensores de la NGP, por otro lado, son más vulnerables a la crítica fatalista si exageran los beneficios previstos por la introducción del nuevo sistema de gestión -éste ha sido un destino compartido por los distintos esfuerzos de reforma administrativa que se han ido sucediendo. Pero incluso en este caso, los fatalistas no ofrecen nada que sirva para sustituir a la NGP más allá de desacreditar escépticamente cualquier propaganda reformista.

\section{La critica individualista}

Desde las teorias culturales, las actitudes individualistas se asocian con una lectura optimista de la naturaleza de las interacciones humanas, como por ejemplo la visión "cornucopiana" sobre las posibilidades de incrementar los recursos naturales disponibles. Los individualistas creen en la primacía de la actividad emprendedora que responde a las señales del mercado, a la que consideran el mejor método para regular el desarrollo social. La crítica individualista sostiene que la NGP es una mezcla insatisfactoria entre las estructuras tradicionales de la Administración Pública y un sistema basado en la fuerza de los contratos y de los derechos legales de los individuos. Los individualistas, por lo tanto, son radicalmente críticos con los aspectos gerenciales de los mercados de la NGP, así como con los acuerdos quasi-con- 
tractuales que no son plenamente vinculantes en términos legales. Los individualistas rechazan las medidas de "corporatización" que se detienen antes de la completa "privatización", así como aquellos aspectos del sistema administrativo que reproducen el tradicional modelo "bigh-group/high-grid" (el carácter vitalicio de los empleados públicos, por ejemplo) ${ }^{4}$.

Para los individualistas, la solución se halla en sustituir los quasi-contratos por contratos jurídicos (por ejemplo, en el diseño de las actividades del NHS o de las NSA s), para así permitir a los usuarios finales de cada servicio la capacidad suficiente para litigar en contra del contrato entre el comprador y el proveedor, en privatizar en lugar de corporatizar, en relacionar los salarios con los rendimientos, o en abandonar el modelo de carrera funcionarial. En este sentido, la crítica individualista, a diferencia de la fatalista, es capaz de generar una agenda de reforma; una agenda construida alrededor de los mercados y de los contratos.

\section{La crítica jerárquica}

Para las teorías culturales, la etiqueta jerárquica incorpora una amplia variedad de puntos de vista vinculados a la gestión centralizada, a la planificación, al profesionalismo o a la tecnocracia. La perspectiva jerárquica confía en la capacidad humana para gestionar la naturaleza, siempre y cuando esta gestión permanezca estrechamente definida y los sistemas humanos y naturales no desborden radicalmente unos determinados límites (momento en el que se producen resultados catastróficos). Aplicando estas ideas al ámbito de la NGP, los jerárquicos mantienen que los reformadores de la NGP deben tener mucho cuidado de no dejar los procesos de cambio sin control, lo cual dañaría irreversiblemente la dirección global de los servicios públicos. Para los jerárquicos, la desestabilización es la mayor amenaza. Subrayan la necesidad de guiar las reformas con mucho tiento para, así, prevenir el desorden y la anarquía -por ejemplo, en el sistema de pago de los servicios públicos o en las normas que regulan las formas de operar de la Administración.

A la perspectiva jerárquica le preocupa la forma en que la NGP desarrolla las habilidades de gestión y reduce el énfasis en los diseños estratégicos o en las capacidades sinópticas. La NGP, piensan, podría acaparar la atención que los altos responsables públicos deberían prestar a otras herramientas de mayor significación cuantitativa. Desde este punto de vista, la eficiencia de la NGP incrementa el riesgo de que las políticas públicas acaben en grandes fiascos. Los factores que explican estas preocupaciones se derivan de la erosión en la capacidad de planificación a medio o largo plazo por parte del gobierno central, y también del fracaso a la hora de establecer un equilibrio adecuado entre la dirección política, el soporte administrativo y los expertos externos. Del mismo modo, alli donde la NGP pone más presión para satisfacer un elenco limitado de objetivos, los jerárquicos se preocupan por reducir los posibles efectos perversos y por animar a los gestores a reducir los desastres previstos a través de transformaciones en la relación costes-beneficios, o a través de negociaciones y de asesorías alternativas (HOOD y JACKSON, 1991). Ellos temen, sobre todo, que el resultado de las políticas pueda derivar en fracasos parecidos a los que provocó la computerización del servicio de ambulancias de Londres en 1992.

A los jerárquicos también les preocupa el riesgo a una erosión de la ética tradicional del servicio público provocada por los cambios que introduce la NGP, desmantelando el concepto de carrera dentro del ámbito público o rediseñando las organizaciones del sector en la línea de las relaciones entre el contratador 0 decisor principal y los agentes. Con la introducción del concepto de ética de los servicios públicos quizá se quiere dar a entender, en el lenguaje de las aproximaciones económico-institucionales modernas, una red de relaciones contractuales basadas en un alto nivel de confianza, en todo el sector público (reflejándose en transacciones de bajo coste en las negociaciones entre las diferentes agencias públicas).

Las soluciones jerárquicas para tales debilidades subrayan la necesidad de mantener o de impulsar una mayor capacidad de control central sobre los servicios públicos. Esta capacidad se podría articular de varias formas, por ejemplo a través de unos órganos reguladores encargados de gestionar los mercados o los quasi-mercados de servicios públicos, o redactando contratos con entes públicos que incorporen la obligación de consultar sobre las políticas (reintroducido en los contratos de los altos ejecutivos públicos neozelandeses en 1991). Si el contrato se convierte en norma, los jerárquicos insisten en la necesidad de desarrollar, dentro del sector público, modelos basados en un alto nivel de confianza en las "relaciones contractuales de obligación" (RCO), en lugar de los modelos de baja confianza de las "relaciones contractuales de delegación" (RCD) ${ }^{6}$, con el objetivo de mantener la capacidad para negociar a través de las fronteras de la organización sin unos costes de transacción excesivos en los momentos de crisis (SAKO, 1991). Al igual que los individualistas, los jerárquicos también son capaces de generar una agenda de reforma alternativa a la de la NGP -aunque, evidentemente, su agenda más probable es diametralmente opuesta a la propuesta desde la perspectiva individualista.

\section{La critica igualitaria}

Desde la teoría cultural, la posición igualitaria es la más pesimista en relación a las interacciones entre la naturaleza y los seres humanos. Consideran que importantes errores de cálculo pueden ser el resultado de procesos de toma de decisiones elitistas y de una acentuada concentración del poder organizativo. En esta dirección, es también la categoría más de "izquierdas" de la tipología cultural que estamos utilizando, aunque no se identifica simplememte con posturas socialdemócratas o socialistas. En relación a la NGP, la crítica igualitaria sostiene que unas reformas de amplio alcance mercantilizador incrementan el riesgo de comupción en el sector público. En ausencia de presiones contrarias, la 
NGP puede reflejar los intereses personales de los altos cargos en detrimento de los de los usuarios de los servicios. El riesgo de la NGP es convertir al gobierno en algo menos comprensible, menos responsable y menos accesible para los ciudadanos; aunque proclame intenciones y objetivos radicalmente contrarios.

El riesgo de aumentar la comupción, la malversación y la parcialidad es constante en las críticas igualitarias a la NGP. Los igualitarios consideran que estos abusos son más fáciles de llevar a cabo en un modelo de responsabilidad descentralizada como el propuesto por la NGP, así como en la extensión de áreas cubiertas por doctrinas de la confidencialidad comercial o de la privacidad de los contratos. El temor es que la creciente interrelación entre los sectores público y privado pueda incrementar los motivos y las oportunidades para la corrupción, y que los intentos de sustituir las actuaciones de línea, con reglas contractuales de bajo coste, por mecanismos más sofisticados de valoración en función de múltiples criterios pueda expandir este potencial -tal como ocurre actualmente con la extensión del CCT (compulsory competitive tendering) al ámbito de los servicios profesionales o de la función pública ?

A los igualitarios también les preocupa que unos altos cargos caracterizados por su vocación de dar forma a las organizaciones (y alejados del estereotipo del burócrata maximizador de presupuestos fomentado por la Escuela de Chicago) consideren que les puede interesar presionar excesivamente en la dirección de estrictos cortes presupuestarios, subcontrataciones o procesos corporativizadores (DUNLEAVY, 1991). Incluso cuando estos cambios reducen el conjunto del bienestar global, pueden beneficiar a los intereses personales de los altos cargos públicos, quienes crearian para su propia satisfacción unas organizaciones estratégicas -pequeñas pero muy poderosas- que se alejarían de todas las complejas dificultades que comporta la aplicación de políticas sobre el terreno. De la misma forma que la policía practica, a pesar de la ideología oficial proclamada por los jefes del servicio, lo que llamaríamos "evitar patrullar" (patrol avoidance) en favor de una más cómoda tarea que se realiza con los colegas en las oficinas o los cuarteles (JONES, 1980), los altos cargos de la Administración pueden tender -a no ser que los incentivos se establezcan con mucho cuidado- a "evitar gestionar" (management avoidance) externalizando culpas y responsabilidades.

Consecuentemente, los igualitaristas señalan el riesgo de una venta o una privatización inadecuada (reductora de bienestar) del sector público, simplemente porque los posibles cambios crean oportunidades para rediseñar las organizaciones públicas hacía unos formatos que se adaptan a los intereses personales de los altos cargos de la Administración. Las élites públicas mejoran sus condiciones de trabajo ( $y$ a menudo también sus beneficios pecuniarios) gracias al rediseño sugerido por la NGP, mientras que los costes de las transformaciones organizativas son soportados por otros intereses menos poderosos y, en espe- cial, por el personal de contacto con los clientes. Estas tendencias pueden verse favorecidas por la introducción de esquemas de responsabilidad que se concentran en un estrecho abanico de costes calculados a través de índices financieros, pero que ignoran los costes más difusos o las alteraciones en la calidad de los servicios que no pueden ser fácilmente cuantificables.

En tercer lugar, a los igualitarios les preocupa el efecto que la fragmentación del gobierno en los niveles central y local pueda tener sobre las políticas públicas -sustituyendo las autoridades con objetivos múltiples y con capacidades para afrontar problemas complejos, desde los propios recursos internos o desde alternativas estratégicas, por pequenos órganos dedicados a un único asunto. La fragmentación crea unidades con objetivos estrechamente delimitados 0 , a menudo, dedicados a la oferta de un único producto. Esta situación multiplica las relaciones interorganizativas y puede generar problemas adicionales, como la pérdida de responsabilidad que provoca el paso de los servicios controlados públicamente a las relaciones contractuales o a la "nueva magistratura" (STEwarT et al., 1992); el déficit de coordinación que acusan los servicios públicos al pasar de ser coordinados políticamente a convertirse en una Administración "sin dirección" (bands'-off administration) controlada por gestores 0 usuarios; la insuficiente capacidad de respuesta política a que nos conduce la sustitución de la burocracia, que puede ser utilizada como herramienta de cambio social (a través de la igualdad de oportunidades o modelando el comportamiento de los empleados públicos), por los imperativos de la competencia; y el riesgo creciente de que los servicios fracasen como resultado del tránsito desde unas organizaciones grandes, con disponibilidad de recursos estratégicos y con capacidad para afrontar los problemas de personal a otras organizaciones relativamente más simples, con recursos escasos y fuertemente vulnerables frente a posibles debilidades de liderazgo.

Aunque gran parte del énfasis de la NGP se coloca sobre la promoción de una gestión cercana al consumidor, la descentrali-

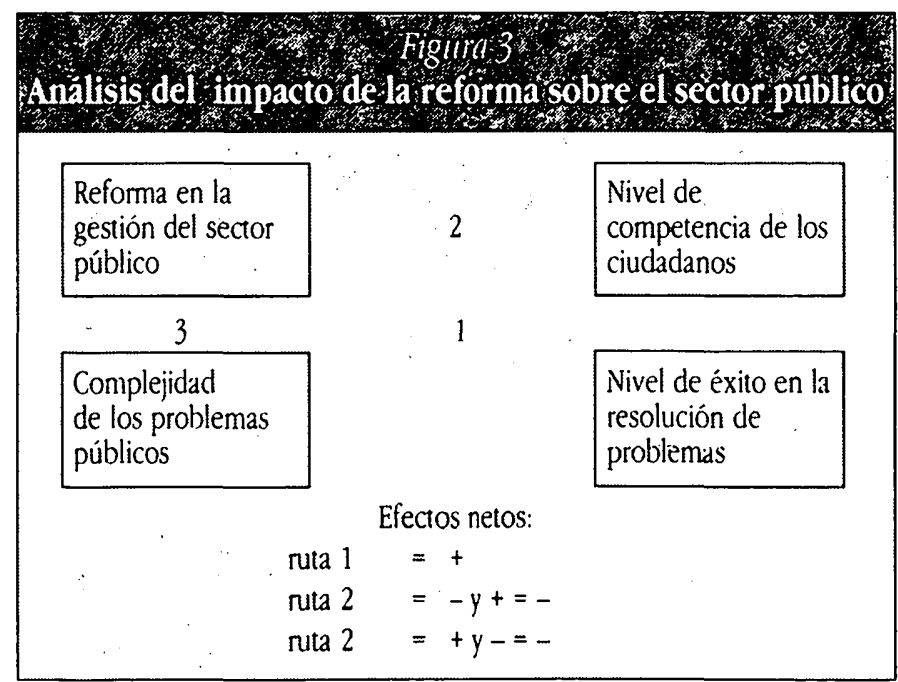


zación y la capacidad de elección por parte del cliente, los igualitaristas subrayan que la coordinación efectiva de los servicios públicos es un tema que preocupa a los ciudadanos. Temen que esta coordinación pueda sufrir a causa de los efectos inducidos por unos órganos excesivamente especializados (single-mission agencies). El riesgo de hacer más transparentes las estructuras gubernamentales radica en que se haga a expensas de la capacidad de los ciudadanos para entender la distribución de responsabilidades entre una jungla de organizaciones que tratan con problemas interrelacionados. Los efectos positivos esperados de la capacidad de la NGP para resolver problemas pueden ser desplazados por efectos no intencionados que presionan en la dirección contraria, incrementando la complejidad de los problemas y reduciendo la capacidad de los ciudadanos tanto para entenderlos como para afrontarlos. El riesgo radica en que estos efectos indirectos puedan debilitar la capacidad para resolver problemas sociales, compensando en parte o totalmente las ganancias en eficiencia que la NGP reclama como mérito propio. La figura 3 resume esta discusión.

\section{Repaso a las cuatro críticas}

En el estado actual de conocimiento, es poco probable que se pueda establecer ningún consenso acerca de cuál de las críticas referidas tiene mayor relevancia. Es más probable que una supuesta discusión empírica en relación a estos asuntos tan complejos estuviera dominada o bien por aquellos defensores de la NGP que exageran las mejoras de eficiencia a partir de una selección previa de los datos, o bien por aquellos detractores que fundamentan su escepticismo en anécdotas singulares o en esbozar argumentos a partir de experiencias pasadas. Lo que sería más fácil es acordar que éstas son las principales líneas de ataque a la NGP. Aunque las críticas son obviamente contradictorias, pueden ayudarnos a apuntar los elementos más vulnerables de la NGP y a identificar las posible soluciones o los ajustes más apropiados a cada tipo de crítica. El diseño organizativo de la NGP se mostrará resistente sólo si puede adaptarse a los diferentes tipos de agendas y si los responsables de gestionar el proceso son capaces de mantener las diferentes críticas en una tensión dinámica, ajustando el diseño básico para acomodarlo a las críticas del momento.

\section{¿Qué nos puede deparar el futuro?}

Observar el paso de la Administración Pública progresista a la NGP desde la óptica de la teoría cultural nos ayuda a entender las críticas presentes, y quizá también las futuras, a la NGP. Es poco probable, además, que estas críticas tiendan a desaparecer. Cada una de ellas enraiza con una visión válida, internamen- te coherente e históricamente recurrente de la gestión pública. A no ser que hayamos superado la historia, la gestión pública del futuro seguirá probablemente un curso zigzagueante entre el fuego cruzado de los diferentes y también contradictorios argumentos críticos. En clara oposición a las opiniones de OsBorne y GAEBlER (1992), según las cuales existe un movimiento inevitable y global hacia un único modelo de NGP, nosotros sugerimos que los posibles escenarios de futuro son múltiples. También defendemos que las reformas del sector público incorporan asuntos que van más allá de las más inmediatas consideraciones de coste y calidad, que alcanzan -en último término- una naturaleza constitucional.

Existen más escenarios de futuro para la gestión pública que los que se incorporan al debate actual desde las atrincheradas posturas ortodoxas. Visiones simple y dicotómicas entre Estado y mercado, o entre estilos tradicionales y modernos de gestión, son de utilidad. Pero también comportan peligros, ya que oscurecen otras posibilidades intermedias de gran importancia. Recuperando los dos tipos básicos de coordinación presentados con anterioridad (aquél que se fija en el nivel de reglas procedimentales del modelo general y aquél que se centra en el grado de separación entre los sectores público y privado), debemos reconocer que el debate actual se concentra casi exclusivamente en los cuadrantes bajos, tanto de la izquierda como de la derecha, de la figura 1; del mismo modo que la mayoría de los comentaristas asumen que la reforma de la gestión pública se dirige inexorablemente hacía la zona sur-oeste. Nosotros pensamos que la posibilidad de que partes importantes del sistema se ubiquen en los otros dos cuadrantes merece alguna atención. La figura 4 modifica la figura 1 y esboza cuatro posibles escenarios de futuro.

Dos de los escenarios de futuro plasmados en la figura 4 (los cuadrantes bajo-izquierda y alto-derecha) ya nos son familiares. El de arriba a la derecha, que hemos denominado Estado buro-

\begin{tabular}{|c|c|c|}
\hline & $\begin{array}{l}\text { Nivel bajo de separación } \\
\text { público.privado }\end{array}$ & $\begin{array}{l}\text { Nivel alto de separación } \\
\text { público-privado }\end{array}$ \\
\hline $\begin{array}{l}\text { Alto grado de gene- } \\
\text { ralización de las re- } \\
\text { glas }\end{array}$ & $\begin{array}{l}\text { Modelo de reja cerrada } \\
\text { Proveedores privados, ma- } \\
\text { nuales de procedimientos } \\
\text { (juridificación), sin media- } \\
\text { ción política. } \\
\text { Ejemplo: La sanidad ame- } \\
\text { ricana en los ochenta. }\end{array}$ & $\begin{array}{l}\text { Estado burocrático } \\
\text { Extender la provisión pú- } \\
\text { blica a través de organiza- } \\
\text { ciones públicas específicas } \\
\text { Ejemplo: El estilo tradicio- } \\
\text { nal del sector público ale- } \\
\text { mán. }\end{array}$ \\
\hline $\begin{array}{l}\text { Bajo grado de gene- } \\
\text { ralización de las re } \\
\text { glas }\end{array}$ & $\begin{array}{l}\text { Estado minimo-comprador } \\
\text { Máxima presencia corpora } \\
\text { tiva, el Estado como "con- } \\
\text { sumidor inteligente". } \\
\text { Ejemplo: El gobierno de } \\
\text { Los Angeles. }\end{array}$ & $\begin{array}{l}\text { Modelo descabezado } \\
\text { Sector público específico } \\
\text { pero turbulento, sin ges- } \\
\text { tores responsables. } \\
\text { Ejemplo: Las Universida- } \\
\text { des británicas. }\end{array}$ \\
\hline
\end{tabular}


crático (public bureaucracy state), se asocia a un sector público específico, con unas competencias básicas y con unas formas de operar distintivas y bien definidas. El escenario de abajo a la izquierda, llamado Estado mínimo-comprador (minimal purchasing state), representa un mundo donde las tareas del gobierno consisten en contratar y donde las grandes empresas privadas dominan la provisión de los servicios públicos, de forma parecida a lo que ha sucedido con los negocios de la comida rápida o a lo que sucedió con las antiguas compañias coloniales al estilo de la East Indian. El cambio tecnológico que está transformando el tronco de las burocracias weberianas en sistemas expertos de procesamiento, descentralizados e intensivos en capital, ha alterado lo que en otro tiempo fueron los procesos de manejo de la información específicos del sector público, trasladando la gestión pública a terrenos donde internacionalmente dominan las grandes corporaciones del sector privado.

Sin embargo, tan interesante como lo descrito antes son los sistemas que no se sitúan en el cuadrante bajo de la izquierda sino en el de la derecha. Hemos etiquetado este sector como el "modelo descabezado" (beadless cbicken model). En este caso, los servicios públicos son a la vez gestionados en exceso y en defecto. Son excesivamente gestionados en el nivel de las organizaciones individuales, pero conjuntamente sub-gestionados, ya que no existe un sistema de dirección. Las reglas generales que se aplican al sector público se relajan o abandonan. Nadie reconoce su propia posición en el sistema. Las tradicionales convenciones de comportamiento se colapsan; hay crecimiento, diversidad, innovación y confusión, pero el sector público aún se mantiene diferenciado respecto al sector privado en términos de personal y de organización. El "modelo descabezado" comporta una estructura donde no existe un responsable identificable de la gestión, lo cual es muy común en las fragmentadas jurisdicciones americanas (y también fomentado por muchas de las reformas actuales, a pesar de o, probablemente, como resultado de sus objetivos de restringir los procesos de rendición de cuentas. Las organizaciones públicas existentes efectúan maniobras dentro de su terreno de juego en función de una racionalidad individual, pero no prestan ninguna atención a la racionalidad colectiva de las estrategias del sector público, ya que no existen normas claras que delimiten responsabilidades y marquen las pautas de trabajo. El gran riesgo del "modelo descabezado" es la transformación gradual de la calidad y los problemas relacionados con la inestabilidad y la sobreposición y confusión de responsabilidades -circunstancias que han guiado la reforma de los centros de las metrópolis británicas y americanas en el pasado.

El "modelo descabezado" no es únicamente una posibilidad abstracta y teórica. Creemos que algunas de las reformas contemporáneas del sector público tienden a situarnos precisamente en este sector de la figura 4 . A pesar de que oficialmente se promociona el cuadrante bajo de la izquierda, en la práctica fuerzas múltiples presionan en esta dirección. Por ejemplo, las grandes diferencias entre las remuneraciones en el sector privado y en el sector público limitan la posibilidad de que gestores privados cualificados y experimentados puedan aterrizar en las organizaciones públicas. De aquí que de facto los cuerpos públicos permanezcan tan estables a pesar de la retórica de su apertura, incluso en Estados con aspiraciones de reforma tan radicales como Nueva Zelanda. Otras barreras legales o de capital pueden ser utilizadas para mantener la especificidad de las organizaciones públicas o semi-públicas, como es el caso de las Universidades o de otras instituciones educativas. La reforma de la gestión pública es propensa al "modelo descabezado", al menos siempre que se produzca el abandono de unas burocracias uniformes e inclusivas. El continuo desarrollo de fuerzas de poder rivales dentro del sector público (por ejemplo, con el desarrollo de reguladores múltiples en la Unión Europea o con la amalgama de autoridades que están reemplazando al uniforme gobierno local tradicional) puede exacerbar las tendencias mencionadas. Lo que no está tan claro es si el "modelo descabezado" es una posibilidad permanente para la gestión pública del futuro o si se trata únicamente de un estilo de gestionar que debe dejar paso a otros. La propia metáfora utilizada implica un estado de transición, una fase inestable más que un resultado permanente. Si el modelo puede realmente actuar indefinidamente, necesitaríamos una nueva metáfora para este estilo de gestión.

Igualmente interesante es el cuadrante alto de la izquierda, al que hemos etiquetado como el "modelo de la reja cerrada" (gridlock model). En el estilo de la "reja cerrada" no se da una distinción estricta entre los proveedores privados y los públicos: incluso muchos de los servicios públicos pueden ser prestados por corporaciones privadas. Sin embargo, al mismo tiempo, se desarrollan normas de procedimiento fuertes y tendencialmente completas (basadas en la amenaza del litigio o sustentadas por una creciente y decidida presión reguladora), de tal manera que la provisión efectiva de los servicios queda muy delimitada por las reglas. El caso de la sanidad americana de los años ochenta es el ejemplo más obvio -y también el más notorio- de este tipo de estructuras, y puede observarse como una ilustración típica de la forma de modelar la gestión pública, un sistema paralizado por un proceso de juridificación totalmente opuesto a las premisas de "libertad para gestionar" que preconizan los libros de texto.

JaCOB (1991), por ejemplo, ha subrayado el potencial de las nuevas posibilidades de litigiosidad que incorpora la reforma sanitaria británica, argumentando que las estructuras mercantiles internas del National Health Service proporcionan cinco poderosas condiciones para una fuerte capacidad de litigio (unas obligaciones legales inciertas, elevadas indemnizaciones, la posibilidad de grandes fracasos, las disputas actuales que diluyen la necesidad de cooperar de las partes contendientes acerca del futuro de la transacción, y la distinción entre los objetivos de los que toman las decisiones y aquéllos para los que trabajan las instituciones). El propio JACOB argumenta: "Sea deseable o indeseable, 
intencionado o no intencionado, muchos de estos cambios probablemente abonarán un fértil campo para los abogados: ellos y sus aliados, especialmente los auditores de cuentas, se convertirán en actores privilegiados dentro del ámbito de la salud".

Tal como sucedía con el "modelo descabezado", tampoco es demasiado complicado identificar las tendencias que conducen la gestión pública hacía el "modelo de la reja cerrada". El aumento de los litigios asociado a las normas de los seguros a todo riesgo, el incremento de la presión reguladora ejercida tanto desde la Unión Europea como desde los propios Estados, y la proliferación de códigos de conducta gubernamentales podrían estar provocando el efecto práctico de alterar la libertad de gestión que reclaman las reformas de la Administración pública actuales, provocando la ubicación del sistema de gestión en la zona del "modelo de la reja cerrada".

Tanto el "modelo descabezado" como el de "la reja cerrada" tienen potencialidades y debilidades. La virtud más obvia del "modelo descabezado" es su capacidad potencial para liberar fuerzas dinámicas y emprendedoras reprimidas, para dar el golpe de gracia a unas estructuras anquilosadas y, en definitiva, para incorporar unas disposiciones de innovación y de competitividad que estaban ausentes de las aproximaciones tradicionales a la gestión pública. En contraste, el "modelo de la reja cerrada" es capaz de evitar las arbitrariedades y los caprichos que un poder de gestión desenfrenado puede incorporar. Podemos también identificar con claridad las correspondientes debilidades. Los aspectos de irresponsabilidad (no-one in charge) del "modelo descabezado" pueden provocar duplicaciones, errores de precio muy elevado y procesos como los descritos por la ley de Gresham, según la cual la mediocridad y la tendencia a la baja de los estándares de calidad nos alejan de las buenas prácticas de la gestión pública. Por su parte, los aspectos reglamentarios más estrictos del "modelo de la reja cerrada" pueden provocar rigideces, así como costes desmesurados y un elevado número de disputas sin resolver.

Un análisis realista de las dinámicas de la gestión pública debería alejarnos de una comparación exclusivamente teórica entre las ventajas y los inconvenientes de los mercados o de las jerarquías $y$, en cambio, llevarnos a considerar también los menos examinados casos intermedios. Como sucede con todos los caminos hechos con la mejor de las intenciones, la ruta hacia un estilo de gestión más mercantil puede desembocar en situaciones inesperadas y desagradables. Sugerimos que, en la práctica, puede fácilmente conducimos o bien hacia el "modelo descabezado" o bien hacia el "modelo de la reja cerrada", o -más probablemente- en primer lugar hacia uno de ellos y más tarde hacia el otro. Si esto es cierto, deberíamos comparar los costes y los beneficios de estos resultados, contrastándolos con las ventajas y las debilidades del modelo del Estado burocrático. La mayor parte del debate actual ignora estas posibilidades intermedias.

\section{Clonificación inapropiada, competencias básicas y el Estado Británico}

Tal como ya hemos señalado, uno de los problemas constantes en la reforma de la gestión pública es la permanente presión de las modas del momento; $y$, en las organizaciones no mercantiles, la necesidad de medir su éxito a través de la opción por un marco ritual y retórico que la gente importante asume como dado. Si la historia de las reformas de la gestión pública nos enseña algo, es que la mayoría de estrategias miméticas o clonificadoras son profundamente inapropiadas para los casos particulares. Quizá los decisores públicos requieren más asesores alternativos 0 , al menos, necesitan ir más allá de las posiciones simplistas del tipo, cuatro brazos mejor que dos, que reducen la variedad de aproximaciones alternativas a la gestión pública, y realizar esfuerzos que les permitan identificar aquellas circunstancias donde dos brazos son mejor que cuatro, o viceversa. Por ejemplo, allí donde la corrupción y el crimen organizado representan una amenaza para la integridad de los servicios públicos, las ventajas potenciales del modelo del Estado burocrático han de reconocerse. Dado que al menos uno de los países de la Unión Europea ha quedado paralizado por el poder del crimen organizado, la experiencia americana de más de un siglo de lucha contra estos delitos (por ejemplo, con intentos de realizar una lista negra de los contratos que van a parar al crimen organizado o incluso evitándolo a través de la instalación de empresas públicas) y la constatación de que la corrupción no es algo del pasado, este tipo de preocupaciones no pueden ser marginadas como únicamente abstractas o teóricas. Alli donde las leyes contractuales ordinarias son inoperantes (como en el caso del poder criminal organizado o cuando la corrupción distorsiona los procesos públicos de contratación), ni siquiera el "modelo de la reja cerrada" puede representar una alternativa efectiva al Estado burocrático. E incluso cuando las leyes contractuales no son minadas por los poderes criminales, el "modelo de la reja cerrada" no es necesariamente la opción de menor coste (sino que puede muy bien comportar costes más elevados).

Bajo el problema permanente de una clonificación inapropiada descansan dificultades más profundas, relacionadas con la asignación de competencias básicas a los Estados de la nueva era. Muchos de los cambios experimentados desde 1945 por el gobierno británico (en particular, la pérdida de capacidad militar autónoma, el desmantelamiento del imperio, la cesión de poder frente a la Unión Europea y los sucesivos ataques al gobierno local) han generado el efecto de transformar en diferentes roles lo que una vez fue la unidad de la política nacional -buscando 
nuevas tareas que sustituyan las anteriores propias de la noción de imperium, convirtiendo a los antiguos decisores en litigadores o implementadores de políticas determinadas fuera de su ámbito, o asumiendo servicios antes realizados por las autoridades locales. Lo preocupante de este proceso es la ausencia absoluta de un debate claro sobre qué competencias básicas deberían -en este nuevo y cambiante contexto- ser retenidas por el sector público nacional y, consecuentemente, qué áreas de la gestión pública deberían continuar siendo dirigidas desde estilos más tradicionales.

Se constata un agudo contraste entre el acento que la literatura gerencial del sector privado sitúa en la identificación y la modificación de las competencias básicas de la empresa, y la ausencia de consideraciones similares en la reforma actual de la gestión pública. En la literatura empresarial, el núcleo de competencias básicas se define como las capacidades intelectuales, gerenciales, de servicio o mercantiles que pueden, de forma continuada, desarrollarse y asegurar la competitividad. Algunos analistas de la gestión empresarial son altamente críticos con las estrategias externas (outsourcing), argumentando que externalizar tareas aparentemente rutinarias puede significar que firmas exteriores se hagan su propio hueco y que se pierda progresivamente la conexión que proporciona el estar involucrado con la producción, perdiendo la posibilidad de identificar nuevas formas de competir y, probablemente, reduciendo el contacto directo con sus consumidores finales.

Contrariamente, las actuales reformas de la gestión pública británica parecen caracterizarse por una tendencia irreflexiva hacia estrategias externalizadoras radicales, sin un debate equivalente entre los partidarios más convencidos de estas posiciones y los defensores de un núcleo básico de competencias internas. En la medida en que las grandes corporaciones privadas se implantan en áreas hasta entonces reservadas exclusivamente al gobierno (como los servicios de justicia criminal), probablemente se aplicarán con éxito muchas de las técnicas de trabajo y de los comportamientos estandarizados por los avances tecnológicos y que han demostrado su efectividad en las industrias privadas. De la misma manera que las corporaciones globales han estimulado y creado extensos mercados alli donde antes sólo existía un localismo, unas compañías de servicios operando transnacionalmente durante el próximo siglo pueden ser capaces de desarrollar habilidades y conocimientos en prácticamente todas aquellas áreas actualmente manejadas y controladas por organismos públicos de prestación de servicios.

Estas ideas plantean interesantes cuestiones. Desde el enfoque del "Estado mínimo-comprador", el papel clave del gobierno debería ser el de consumidor inteligente de servicios, como también debería estar provisto de una diversidad de actores subcentrales o privados -agencias, quasi gobiernos, corporaciones privadas, órganos micro locales y autoridades municipales residuales. El rol del Estado se define, utilizando una famosa expresión de Osborne y Gaebler (1992), en términos de "timonear en vez de remar". Si se implanta esta visión diversificada, se generarán nuevos y más complejos tipos de "comunidades de políticas" (policy communities). Pero si esta visión diversificada no es efectiva, sino que se desarrolla a través de unas pocas corporaciones gigantes cuyos expertos y mercados sacuden y limitan las capacidades públicas de Estados pequeños o medianos, las dificultades para retener cualquier capacidad real de control gubernamental (de timonear) podrían verse enormemente incrementadas. Tal como mencionábamos anteriormente, es ya problemático el desarrollo de sistemas de información públicos, los cuales representan un área fundamental donde mantener la competencia gubernamental. Si en el futuro se produce un desarrollo radical y global de la corporatización de los servicios públicos, otros ámbitos de las políticas públicas pueden seguir esta misma dirección.

El modelo del Estado burocrático continúa siendo relevante en aquellas áreas donde el gobierno necesita (al igual que aquellas corporaciones que intentan proteger sus capacidades claves) hacer algo más que simplemente escoger entre un menú de bienes y servicios, cuyos orígenes y dinámicas se desarrollan fuera de su control. Hasta el momento, el debate sobre las reformas de la gestión pública no ha tenido éxito en lo que debería ser su tarea central: delimitar las funciones esenciales del gobierno. El peligro es que un juicio global acerca del núcleo básico de competencias gubernamentales se formule sólo incrementalmente, a través de un proceso de residualización de soluciones externas aplicadas sin criterio fijo a diferentes ámbitos de trabajo. Esta forma de proceder comportó desastres en la industria americana de la manufactura de los ordenadores, donde durante los años ochenta se externalizó demasiado extensivamente y se perdió su posición en el mercado. Fácilmente, en ausencia de una presión contraria para identificar, proteger, mantener y desarrollar su propio núcleo de competencias, podría pasar lo mismo a los gobiernos nacionales. De este modo, lo que se está dilucidando con estas reformas no son simples asuntos operativos, de costes y respuestas a corto término (bread-and-butter issues). En última instancia el debate es por así decirlo constitucional, ya que afecta a los propios fundamentos y capacidades de la política.

\section{Agradecimientos}

Este articulo fue redactado originalmente para el primer seminario LSE/Cabinet Office, esponsorizado por la ESRC y que se celebró en Londres en mayo de 1993. Nos gustaría dar las gracias a todos los participantes, ya que en este artículo revisado hemos utilizado libremente algunos de los elementos de la discusión. También queremos mostrar nuestro agradecimiento a Francis TERRY por sus útiles consejos y comentarios. 
Artículo traducido por Quim Brugué

- Patrick Dunleavy es Catedrático de Ciencia Política en la London School of Economics, y Christopher Hood es Catedrático de Administración Pública de la misma instiución británica.

' Nota del traductor: Aunque quizá sea dificil de entender para aquellos lectores no familiarizados con el tema, la traducción de "low-trust principalagent relationship" ha sido lo más literal posible, ya que su utilización en el lenguaje académico es muy frecuente.

${ }^{2}$ Nota del traductor: Los términos exit option y voice option son muy frecuentes en la literatura politológica. Su precursor, Hirshman, los ha desarrollado en obras como Shifting Involvements: Private Interests and Public Action, publicada por Princeton University Press en 1982.

${ }^{3}$ Nota del traductor: El libro mencionado ha ejercido un rápido y profundo impacto no sólo en el mundo académico, sino también en ámbitos politicos y profesionales. Su traducción al castellano ha sido publicada por la editorial Paidós de Barcelona en 1994. También podemos encontrar una versión castellana del programa de reforma de la Administración Clinton, editada por el vice-presidente Al Gore y publicada por el IVAP (Instituto Vasco de Administración Pública) en 1993.

4 Nota del traductor: Hemos mantenido la terminología original, pero recordamos que una administración pública bigh-group/high-grid es aquella que fun- ciona a través de una lógica altamente diferenciada respecto del sector privado y a través de unas estructuras internas altamente reglamentadas y uniformes.

'Nota del traductor: National Health Service (NHS) y Next Steps Agencies (NST). Como bien saben nuestros lectores, el periodo de gobiemo de Margaret Thatcher supuso una profunda reforma del NHS, orientada básicamente desde criterios mercantiles que pretendian mejorar la competitividad de los servicios sanitarios y ofrecer a sus usuarios la posibilidad de escoger entre prestaciones altemativas. Por su parte, el NSA fue la última iniciativa thatcherista para modernizar la Admjnistración pública británica. Desde las premisas ya expuestas, se pretendia desmontar la gran jerarquía administrativa y dar paso a una pluralidad de entes semjautónomos y con responsabilidad plena sobre las tareas encomendadas.

${ }^{6}$ Nota del traductor: La traducción de los conceptos de este párrafo es compleja. Sin embargo, intentando conservar más la idea que la literalidad, he traducido "obligational contract relationships" y "arms' length contract relationships" por "relaciones contractuales de obligación" y "relaciones contractuales de delegación", respectivamente.

' Nota del traductor: El Compulsory Competitive Tendering fue introducido a finales de la década de los ochenta en Gran Bretaña. Se trata de una legislación que obliga a los municipios a competir en el mercado (con competidores privados) por la prestación de determinados servicios. Su introducción ha sido muy polémica, aunque esto no ha evitado que el número de servicios sujetos a esta legislación continúe aumentando.

\section{Bibliografia}

DOUGLAS, M. (1982) In the Active Voice, Routledge, Londres.

Dunleavy, P.J. (1991) Democracy, Bureaucracy and Public Cboice, Harvester Wheatsheaf, Hemel Hempstead.

Hood, C. y Jackson, M.W. (1991) "The New Public Management: A Recipe for Disaster?" en Parker,D. y Handmer.J. (eds.) Hazard Management and Emergency Planning, James and James, Londres.

JACOB, J. (1991) "Lawyers go to Hospital", Public Law, verano, pp. 255-281.

JONES, J.M. (1980) Onganizational Aspects of Police Behaviour, Gower, Famborough.
Osborne, R. y GaEbler, T. (1992) Reinventing Govermment, Addison Wesley, Wokingham.

PolsBy, N.W. (1984) Political Innovation in America, Yale University Press, New Haven.

SaKo, M. (1991) "The Role of 'Trust' in Japanese Buyer-Seller Relationship", Ricerche Economiche, 45, pp. 449-474.

Schwarz, M y Thompson, M. (1990) Divided We Stand, Harvester Wheatsheaf, Hemel Hempstead.

Stewart, J., LeWTS, N. y LongleY, D. (1992) Accountability to the Public Sector, European Policy Forum. 